\title{
Communication during patient handoff in the areas of intensive care of a university hospital. A cross-sectional study
}

\author{
César A. Belziti, M.D., ${ }^{a}$ Alfredo Eymann, M.D., ${ }^{a}$ Eduardo Durante, M.D., ${ }^{a}$ \\ Rodolfo Pizarro, M.D., ${ }^{a}$ Silvia Carrió, B.S., ${ }^{a}$ and Marcelo Figari, M.D. ${ }^{a}$
}

\begin{abstract}
Objective. To assess how the quality of communication is perceived during patient handoff in areas of intensive care.

Materials and Methods. Cross-sectional study conducted at a university hospital. The study assessed the perception of the quality of information received during patient handoff and the chance of physicians working on-call shifts in intensive care areas mistaking the information of one patient with that of another one.

Results. Information was perceived as being "good" quality when patient handoff took place in pediatric areas $(85.7 \%)$, it was conducted in a calm environment $(74.4 \%)$, it was performed according to a case presentation system $(82.9 \%)$, the physician was responsible for less than 17 patients $(91 \%)$, and training on handoff communication had been provided $(87.5 \%)$.

No significant association with the rest of the analyzed outcome measures was observed.

The chance of mistaking information of one patient with that of another one was perceived as "low" when handoff took place in pediatric areas $(95.2 \%)$, it was performed according to a case presentation system $(80 \%)$, there were not more than three interruptions $(84.6 \%)$, the physician was responsible for less than 17 patients $(90.9 \%)$, training on handoff communication had been provided $(91.7 \%)$, and the physician was a staff doctor $(77.1 \%)$.

Conclusions. The quality of information received during patienthandoff and the chance of mistaking the information of one patient with that of another one were associated with environmental, organizational and educational aspects that can potentially be improved.
\end{abstract}

Key words: patient handoff, intensive care, quality of care, communication.

a. Medical Education Research

Committee, Department of Teaching and Research. Hospital Italiano de Buenos Aires.

E-mail Address:

Alfredo Eymann, M.D. alfredo.eymann@ hospitalitaliano.org.ar

Conflict of Interest: None.

Received: 5-8-2013 Accepted: 8-28-2013 http:/ /dx.doi.org/10.5546/aap.2014.eng.119

\section{INTRODUCTION}

Patient handoff is an interactive process that involves communicating specific patient information and transferring responsibilities in order to maintain a safe continuum of care. Patient handoff takes place when a patient is moved from one area to another or when a physician starts a new shift, which is the usual dynamics in intensive care units. ${ }^{1,2}$
Handoff failures can lead to inadequate patient care..$^{3,4}$ In the context of organizational learning, an adequate handoff is considered necessary to maintain training and consistency across the working team. ${ }^{5}$

Continuous assessments, interventions and multiple tests conducted in intensive care areas result in a large amount of information, which is used as the basis for making decisions. Information omission or misrepresentation can cause medical errors. $^{6}$

Diagnostic and treatment errors can be the consequence of inadequate information at this stage. In the United States, it is estimated that between 44000 and 98000 patients die each year due to medical errors that occur during the care process. ${ }^{7}$ Studies focused on the analysis of medical errors, such as the study conducted in Australian hospitals, found that the most common error was related to inadequate medical communication and that is was associated with increased mortality. ${ }^{8}$

In spite of the relevance given to an adequate communication and training recommendations on communication skills, both with patients and other health care professionals, research on these issues, specifically patient handoffs, has been scarce and is not usually discussed in the literature for practicing physicians, who are the ones involved in this process. ${ }^{9,10}$

Intensive care units are the suitable environment for the study of patient handoffs.

The objective of this study was to assess the perception of communication quality during patient handoff in intensive care areas. 


\section{POPULATION AND METHODS}

This was an observational, cross-sectional study conducted at a university hospital of the City of Buenos Aires with 740 beds distributed in two facilities, 85 of these beds are for adult intensive care and 48 , for pediatric intensive care.

Patient handoff is defined as the oral transmission of information on patients from one physician to another who will be responsible for continuing with such patient's care.

A questionnaire with the following outcome measures was prepared to evaluate the perception of communication: working area, age, graduation year, sex, being a staff physician or a resident, and day of the week.

We also included 18 questions regarding facilitators and barriers of communication in the environmental domain (number of interruptions and whether it was possible to concentrate in the area); organizational domain (number of patients under their care, number of reporting physicians, duration of handoff, case presentation system, emergency decision making, additional information enquiries, and behavior when facing complications); family domain (conflicts among family members and warning of possible family conflicts, preferences regarding life support measures in terminally ill patients), and educational domain (having received training on handoff communication during graduate or postgraduate courses and whether it was considered useful).

Outcome measures were defined as nominal, categorical or continuous, as applicable.

Once the questionnaire was developed, its comprehension was adjusted based on a test run performed on 15 physicians who were not included in the study and who confirmed its apparent validity.

All intensive care unit physicians were invited to participate voluntarily. The survey was completed by participants immediately after ending their shift in a self-administered and anonymous manner in August 2011.

Dependant outcome measures were "perception of the quality of the received information" and "chance of mistaking one patient's information with that of another one." A five-option Likert scale was used for these two outcome measures, and they were dichotomized into: "poor" (very poor-poor-regular) and "good" (good-very good) for the first outcome measure, and "low" (almost null-scarce) and "high" (medium-high-very high) for the second one, as per Streiner and Norman's recommendation. ${ }^{11}$
The $\chi_{2}$ test was applied and a $p$ value lower than 0.05 was considered significant. Cronbach's alpha coefficient was used for estimating reliability. The Stata 8.0 (Texas, USA) software was applied for statistical analysis. The study was approved by the Research Protocol Assessment Committee of Hospital Italiano de Buenos Aires.

\section{RESULTS}

Fifty-one surveys were completed by all physicians who work on-call shifts at the 21 pediatric and 30 adult intensive care areas.

Table 1 describes the characteristics of physicians and the patient handoff process.

A high or very high importance was given to the information received during handoffs by $8.5 \%$ of physicians, information quality was perceived as good or very good by $68 \%$, while the chance of mistaking the information of one patient with that of another one was perceived as almost null or scarce by $66.6 \%$ of respondents.

Information was perceived as being "good" quality when patient handoff took place in pediatric areas, it was conducted in a calm environment, it was performed according to a case presentation system, the physician was responsible for less than 17 patients, and training on handoff communication had been provided. No significant association with the rest of the analyzed outcome measures was observed (Table 2).

The chance of mistaking the information of one patient with that of another one was perceived as "low" when handoff took place in pediatric areas, it was performed according to a case presentation system, there were not more than three interruptions, the physician was responsible for less than 17 patients, training on handoff communication had been provided, and the physician was a staff doctor (Table 3).

Cronbach's alpha coefficient was 0.71 .

\section{DISCUSSSION}

Patient handoff is a practice necessary to maintain the continuum of care in intensive care units. In spite of this statement, there are no defined rules for handoff development nor it is formally included in medical syllabi, although more importance has been given recently to promote such communication skills. ${ }^{23,24}$ There are no established and accepted rules regarding many aspects related to this process: how long should a handoff last?, is is acceptable to refer to medical records for making an emergency decision?, from how many physicians should information 
TABLE 1. Characteristics of physicians and handoff process

Physicians $(\mathrm{n}=51)$

Age (median-IQR)

32 (29-38) years old

Male gender (\%)

58.8

Received training on handoff communication (\%)

47

Considers training on handoff communication useful (\%)

94

\section{Patient handoff}

Number of patients under their care during shift (median-IQR)

Number of patients under their care known before shift (median-IQR)

Number of reporting physicians (median-IQR)

Duration of handoff (median-IQR)

$3(1-5)$

Physicians working weekend shifts (\%)

$60(40-70)$ minutes

More than three interruptions during handoff (\%)

21.6

Calm environment (\%)

Compliance with a case presentation system (\%)

76.9

Communication of possible family conflicts (\%)

Communication of patient's or family's preference regarding the limitation

of life support measures in terminally ill patients (\%)

79

Events occurred during handoff

Made emergency decisions (\%)

Faced family conflicts (\%)

51

IQR: 25-75 interquartile range.

TABLE 2. Perception of quality of information received during patient handoff

\begin{tabular}{lccc}
\hline & Poor (\%) & Good (\%) & $* p$ value \\
\hline Pediatric area & 14.3 & 85.7 & 0.02 \\
Adult area & 43.3 & 56.7 & 0.03 \\
Calm environment & 28.6 & 74.4 & \\
Agitated environment & 62.5 & 37.5 & 0.001 \\
Compliance with a case presentation system & 17.1 & 82.9 & 0.002 \\
Non compliance with a case presentation system & 62.5 & 37.5 & 91 \\
Less than 17 patients under their care & 9 & 51.7 & 0.006 \\
17 or more patients under their care & 48.3 & 87.5 & \\
Received training on handoff communication & 12.5 & 51.9 & \\
Did not receive training on handoff communication & 48.1 & & \\
\hline
\end{tabular}

${ }^{*} \chi 2$ test.

TABLE 3. Perception of chance of mistaking the information of one patient with that of another one

\begin{tabular}{|c|c|c|c|}
\hline & Low $(\%)$ & High (\%) & * $p$ value \\
\hline Adult area & 95.2 & 4.8 & \multirow{2}{*}{0,0003} \\
\hline Compliance with a case presentation system & 46.7 & 53.3 & \\
\hline Non compliance with a case presentation system & 80 & 20 & \multirow{2}{*}{0,002} \\
\hline Less than 17 patients under their care & 37.5 & 62.5 & \\
\hline 17 or more patients under their care & 90.9 & 9.1 & \multirow{2}{*}{0,001} \\
\hline Received training on handoff communication & 48.2 & 51.8 & \\
\hline Did not receive training on handoff communication & 91.7 & 8.3 & \multirow{2}{*}{0,0004} \\
\hline Staff physician & 44.4 & 55.6 & \\
\hline Resident & 77.1 & 22.9 & \multirow{2}{*}{0,03} \\
\hline Adult area & 46.7 & 53.3 & \\
\hline Less than three interruptions & 84.6 & 15.4 & \multirow{2}{*}{0.005} \\
\hline Three or more interruptions & 48 & 52 & \\
\hline
\end{tabular}

${ }^{*} \chi 2$ test. 
be received? Therefore, it can be inferred that no actual criteria are available.

Questions included in the questionnaire took into account elements already accepted in the literature as probable communication barriers which cover environmental, organizational, family and educational domains. ${ }^{12,13}$

Results show that both quality of information and the chance of mistaking information were associated with environmental, organizational and educational aspects. This is valuable information that can be used in quality of care improvement programs and to reduce medical errors. As a result, the study of handoff strategies has received more attention over the past years. ${ }^{14}$

The physician to physician oral, "face-toface" strategy is used in this institution, which was favorably compared to computer-mediated electronic transmission. ${ }^{14}$

However, other studies have demonstrated that using only oral communication was inadequate because it led to missing a large percentage of information. When oral communication is accompanied by a written record, the amount of recalled information was higher and it was even better when a pre-printed template was used; therefore, this latter method is the most recommended one. ${ }^{15,16}$

In a study conducted in six Danish hospitals, $52 \%$ of errors originated in the oral communication of information. Processes most commonly associated with errors were poor telephone communication, transferring a patient from one area to another, and cross-specialty consultation. Authors discourage relying only on oral transmission, especially in the situations mentioned before. ${ }^{17}$

Our study reveals that physicians perceived the information received as being "good" quality and with a "low" chance of mistaking it with that of another patient if cases were presented in the same order. Over the past years, different rules were described so as to organize handoffs with the purpose of following the same approach when proving a report and not missing information. A systematic review identified 24 mnemotechnical rules related to this issue. The SBAR (situation, background, assessment, recommendations) is the most commonly mentioned in the bibliography, but no robust studies have demonstrated the usefulness of any of the currently used rules. ${ }^{18}$

In some fields requiring a high precision, such as air traffic control, strict and systematic rules are followed in each change of shift. ${ }^{19}$
One study analyzed the change of shift in relation to tasks where failure could lead to severe consequences. A space center and a railway distribution center in the United States, and two nuclear power plants and an ambulance distribution center in Canada were included. Based on data analysis, it was concluded that "face-toface" communication was highly important given the non-verbal component of communication; also significant were the presence of a third party who would help with information recalling and comprehension, data repetition by the recipient of information, avoiding interruptions and not performing other tasks during change of shift, and delivering a written report. ${ }^{20}$

In our study, $51 \%$ of physicians reported some sort of "family conflict" during their shift. Although it is a very general term which can entail various levels of complexity and also be perceived differently by physicians, it is noteworthy that this outcome was mentioned by a high percentage of on-call physicians, and although in many cases (74\%) they were warned of a possible family conflict, it is an aspect that points to the need of specific preparation so as to avoid such conflict or, if occurred, to solve it. ${ }^{21,22}$

Staff physicians had a lower perception of a chance of mistaking information of one patient with that of another one when compared to residents. This could be indicative of a sign of a broader experience.

Other aspect to consider is the scarce training on handoff communication. More than half of all physicians did not receive any training during their graduate and postgraduate courses regarding how to communicate information to their colleagues, and most of them considered it useful.

A recent meta-analysis included 10 studies which implemented educational interventions aimed at improving patient handoffs and concluded that they could help to improve the process but given the design or sample size, it was not possible to demonstrate such usefulness and there are still no studies showing a modification in patient prognosis. Other encouraging conclusion is that, in spite of little information available on this issue, it has increased over the past years. ${ }^{23}$

Some of the limitations of the study may be that a complex construct such as communication was assessed using a survey and the number of surveyed individuals was not sufficient to make a multivariate analysis. Notwithstanding such limitation, results obtained are considered plausible. 


\section{CONCLUSIONS}

It is concluded that the perception of quality of information and the chance of mistaking information during patient handoff were associated with environmental, organizational and educational aspects. Data obtained indicate possible scopes for handoff improvement interventions and pose encouraging questions for future research in this field.

\section{REFERENCES}

1. Haggerty JL, Reid RJ, Freeman GK, Starfield BH, et al. Continuity of care: a multidisciplinary review. $B M J$ 2003;327:1219-21.

2. Greenberg CC, Regenbogen SE, Studdert DM, Lipsitz SR, et al. Patterns of communication breakdowns resulting in injury to surgical patients. J Am Coll Surg 2007;204:533-40.

3. Pronovost $\mathrm{P}$, Thompson D, Holzmueller CG, Lubomski $\mathrm{LH}$, et al. Toward learning from patient safety reporting systems. J Crit Care 2006;21:305-15.

4. Arora V, Johnson J, Lovinger D, Humphrey J, Meltzer DO. Communication failures in patients sign-out and suggestionsforimprovements: acriticalincidentanalysis. Qual Saf Health Care 2005;14:401-7.

5. Pickering BW, Hurley K, Marsh B. Identification of patient information corruption in the intensive care unit: Using a scoring tool to direct quality improvements in handover. Crit Care Med 2009;37:2905-12.

6. Sutcliffe KM, Lewton E, Rosenthal MM. Communication failures: an insidious contributor to medical mishaps. Acad Med 2004;79:186-94.

7. Kohn LT, Corrigan JM, Donaldson MS, editors. To err is human. Building a safer health care system. Committee on Quality and Healthcare in America. Washington DC: Institute of Medicine. National Academy Press; 2000.

8. Wilson RM, Runciman WB, Gibberd RW, Harrison BT, et al. The Quality in Australian Health Care Study. Med J Aust 1995;163:458-71.

9. Frank JR, ed. The CanMEDS 2005 Physician Competency Framework. Better standards. Better physicians. Better care. Ottawa: Royal College of Physicians and Surgeons of Canada; 2005.

10. Accreditation Council for Graduate Medical Education. 2001. Outcome project timeline-Working guidelines. [Accessed on: December 4, 2010]. Available at: http: / / www. acgme.org / outcome / project / timeline / TIMELINE_index_frame.htm

11. Streiner DL, Norman GR. Health measurement scales. A practical guide to their development and use. 4th. ed. Oxford: Oxford University Press; 2008.

12. Ilan R, LeBaron CD, Christianson MK, Heyland DK, et al. Handover patterns: an observational study of critical care physicians. BMC Health Serv Res 2012;12:11.

13. Burbano O'Leary SC, Federico S, Hampers LC. The truth about language barriers: one residency program's experiency. Pediatrics 2003;111:e569-73.

14. Solet DJ, Norvell JM, Rutan GH, Frankel RM. Lost in translation: challenges and opportunities in physician- to -physician communication during patients handoffs. Acad Med 2005;80:1094-9.

15. Bhabra G, Mackeith S, Monteiro P, Pothier DD. An experimental comparison of handover methods. Ann $R$ Coll Surg Engl 2007;89:298-300.

16. Wayne JD, Tyagi R, Reinhardt G, Rooney D, et al. Simple standardized patient handoff system that increases accuracy and completeness. J Surg Educ 65:476-85.

17. Rabol LI, Andersen ML, Ostergaard D, Bjorn B, et al. Descriptions of verbal communication errors between staff. An analysis of 84 root cause analysis-reports from Danish hospitals. BMJ Qual Saf 2011;20:268-74.

18. Riesenberg LA, Leitzsch J, Little BW. Systematic review of handoff mnemonics literature. Am J Med Quality 2009;24:196-204.

19. Kanki BG, Lozito S, Foushee HC. Communication indices of crew coordination. Aviat Space Environ Med 1989;60:5660.

20. Patterson ES, Roth EM, Woods DD, Chow R, Gomes JO. Handoff strategies in settings with high consequences for failure: lessons for health care operations. Int J Qual Health Care 2004;16:125-32.

21. Volpp KGM, Grande D. Residents suggestions for reducing errors in teaching hospitals. N Engl J Med 2003;348:851-5.

22. Mauksch LB, Dugdale DC, Dodson S, Epstein R. Relationship, communication, and efficiency in the medical encounter: creating a clinical model from a literature review. Arch Intern Med 2008;168(13):1387-95.

23. Findley GM. Educational interventions to improve handover in health care: a systematic review. Med Educ 2011;45:1081-9.

24. Wohlauer MV, Horwitz LI, Bass EJ, Mahan SE, et al. The patient handoff: a comprehensive curricular blueprint for resident education to improve continuity of care. Acad Med 2012;87:411-8. 